\title{
The fraction of activated $N$-methyl-D-Aspartate receptors during synaptic transmission remains constant in the presence of the glutamate release inhibitor riluzole
}

\author{
G. Rammes $\cdot$ W. Zieglgänsberger $\cdot$ C. G. Parsons
}

Received: 28 November 2007/ Accepted: 26 April 2008/Published online: 21 May 2008

(C) The Author(s) 2008

\begin{abstract}
Excessive $N$-methyl-D-aspartate (NMDA) receptor activation is widely accepted to mediate calciumdependent glutamate excitotoxicity. The uncompetitive, voltage-dependent NMDA receptor antagonist memantine has been successfully used clinically in the treatment of neurodegenerative dementia and is internationally registered for the treatment of moderate to severe Alzheimer's disease. Glutamate release inhibitors (GRIs) may also be promising for the therapy of some neurodegenerative diseases. During the clinical use of GRIs, it could be questioned whether there would still be a sufficient number of active NMDA receptors to allow any additional effects of memantine or similar NMDA receptor antagonists. To address this question, we determined the fraction of NMDA receptors contributing to postsynaptic events in the presence of therapeutically relevant concentrations of the GRI riluzole $(1 \mu \mathrm{M})$ using an in vitro hippocampal slice preparation. We measured the charge transfer of pharmacologically isolated excitatory synaptic responses before and after the application of the selective, competitive NMDA receptor antagonist D-AP5 $(100 \mu \mathrm{M})$. The fraction of activated NMDA receptors under control conditions did not differ from those in the presence of riluzole. It is therefore likely that NMDA
\end{abstract}

G. Rammes $(\bowtie) \cdot$ W. Zieglgänsberger

Clinical Neuropharmacology,

Max Planck Institute of Psychiatry,

Kraepelinstraße 2, 80804 Munich, Germany

e-mail: rammes@mpipsykl.mpg.de

G. Rammes

Department of Anaesthesiology, Technische Universität,

81675 Munich, Germany

C. G. Parsons

Merz Pharmaceuticals, 60318 Frankfurt, Germany receptor antagonists would be able to exert additional therapeutic effects in combination therapy with GRIs.

Keywords Amyotrophic lateral sclerosis - ALS .

Memantine · Riluzole · EPSC · Hippocampus ·

NMDA receptor

\section{Introduction}

Glutamate is the major excitatory neurotransmitter in the central nervous system (CNS). However, glutamatergic dysfunction/excitotoxicity is also widely believed to be involved in acute neurodegeneration (e.g., stroke and trauma), chronic neurodegeneration (e.g., Parkinson's disease, Alzheimer's disease, Huntington's disease, and amyotrophic lateral sclerosis-ALS) as well as in the symptomatology of numerous neurological and psychiatric disorders (e.g., epilepsy, Parkinson's disease, drug dependence, depression, anxiety and chronic pain) (Beal 1995; Danysz and Parsons 2002; Parsons et al. 1998; Plaitakis et al. 1996). Glutamate activates postsynaptic receptors, including ionotropic 2-amino-3-(3-hydroxy-5-methylisoxazol-4-yl) proprionate (AMPA) and $N$-methyl-D-aspartate (NMDA) receptors allowing the influx of $\mathrm{Ca}^{2+}$ ions-especially though the later and, in some cases, the former if edited GluR2 subunits are absent (Burnashev et al. 1992). Although physiological elevations in intracellular $\mathrm{Ca}^{2+}$ are salient to normal cell functioning, the excessive or persistent influx of $\mathrm{Ca}^{2+}$ together with any $\mathrm{Ca}^{2+}$ release from intracellular compartments can overwhelm $\mathrm{Ca}^{2+}$-regulatory mechanisms and lead to cell death/excitotoxicity (Arundine and Tymianski 2003; Danysz and Parsons 2002; Krieger et al. 1996; Muir et al. 1995; Wenk et al. 2006) and additionally to symptomatological disturbances, especially those involving 
pathological long-term plastic changes (e.g., chronic pain, drug abuse, epilepsy) (Arundine and Tymianski 2003; Parsons et al. 1998, 2007; Rogawski 2006).

Data from animal models clearly suggest that modulation of glutamate function may be highly beneficial in the treatment of various neurodegenerative/neurological disorders in humans. Reduced glutamate tone may be achieved by different pharmacological interventions, two of which are especially important for the present study: first, antagonising/modulating post-synaptic receptors such as NMDA receptors and second, reducing glutamate release/or increasing uptake at pre-synaptic glutamatergic terminals.

Memantine is a clinically very well tolerated uncompetitive NMDA receptor antagonist (Chen et al. 1992; Parsons et al. 1993, 2007) and its protective effects have been shown in various models of acute and chronic neurodegeneration (Chen and Lipton 1997; Chen et al. 1992; Miguel-Hidalgo et al. 2002; Wenk et al. 1997; for review see Parsons et al. 1999, 2007; Wenk et al. 2006).

The application of so-called glutamate release inhibitors (GRIs) e.g., riluzole, lamotrigine, phosphophenytoin, gabapentin, pregabalin and lubeluzole may be another promising approach for the therapy of neurodegenerative diseases due to their mode of action: blockade of overactive glutamate transmission before it becomes neurotoxic or impedes neuronal discharges during seizures (Parsons et al. 1998). Lamotrigine, for example is an anti-epileptic agent, whereas lubeluzole has been reported to be effective in patients with acute ischaemic stroke (Diener 1998). Riluzole moderately slows disease progression in ALS patients (Bensimon et al. 1994; Lacomblez et al. 1996) and is currently the only approved drug for the treatment of ALS (Gordon 2005; Miller et al. 2007; Parsons and Danysz 2002; Traynor et al. 2006; Van Damme et al. 2005).

The effects of riluzole on the glutamatergic system has been claimed to have both a pre- and postsynaptic locus, although the evidence for the former is more conclusive (MacIver et al. 1996) for reviews see (Doble 1996; Gordon 2005; Miller et al. 2007; Parsons and Danysz 2002; Traynor et al. 2006; Van Damme et al. 2005). Both, in vitro and in vivo experiments have provided data indicating that riluzole has a higher potency to decrease NMDA-evoked responses than those mediated by non-NMDA receptors see (Mantz 1996). It is widely accepted that the effects of rilzuole in ALS are, at best, moderate, and that a combination of drugs with different mechanisms of action might be a more promising therapeutic approach (Goodall and Morrison 2006; McGeer and McGeer 2005; Van Den Bosch et al. 2006; Weiss et al. 2004). However, it remains an open question whether there would still be a sufficient number of active NMDA receptors available during riluzole therapy to allow any additional effect of NMDA receptor antagonists if such compounds were administered in combination with riluzole in order to increase the treatment effect size in this very severe disorder.

When taken as an example indication, clinical monotherapy trials in ALS are probably not ethically justifiable due to the severity of this disease. Moreover, other glutamatergic combination therapies show promise in various animal models and can increase therapeutic effects whilst even reducing side effects-the best preclinical example might seem to be the combination of AMPA and NMDA receptor antagonists in epilepsy (Löscher et al. 1993). In the present study we recorded evoked synaptic events in the CA1 region of murine hippocampal brain slices to determine the magnitude of the NMDA receptor contribution after the application of clinically relevant concentrations of riluzole.

Whilst the spinal cord is probably the main target tissue for the therapeutic effects of riluzole in ALS, we chose to use hippocampal slices as a model tissue relevant for the combined use of GRIs and NMDA receptor antagonists in numerous other indications where therapeutic efficacy of either treatment has been implicated by preclinical studies. NMDA receptors are highly expressed and play a pivotal role in glutamatergic transmission in this structure.

\section{Material and methods}

\section{Brain slice preparation}

Sagital hippocampal slices ( $300 \mu \mathrm{m}$ thick) were obtained from young adult (6-8 weeks) male mice that were anaesthetized with ether before decapitation. The experimental protocols were approved by the Ethical Committee on Animal Care and Use of the Government of Bavaria, Germany. The brain was rapidly removed, and slices were prepared in ice-cold Ringer solution using a vibroslicer (Microm, Walldorf, Germany). To minimize epileptiform activity the $\mathrm{CA} 3$ region was removed. All slices were placed in a holding chamber for at least $60 \mathrm{~min}$ and were then transferred to a submerged superfusing chamber for extracellular or whole-cell recordings. The flow rate of the solution through the chamber was $1.5 \mathrm{ml} / \mathrm{min}$. The composition of the extracellular solution was $124 \mathrm{mM} \mathrm{NaCl}$, $3 \mathrm{mM} \mathrm{KCl}, 26 \mathrm{mM} \mathrm{NaHCO}, 2 \mathrm{mM} \mathrm{CaCl}, 1 \mathrm{mM}$ $\mathrm{MgSO}_{4}, 10 \mathrm{mM}$ D-glucose, and $1.25 \mathrm{mM} \mathrm{NaH}_{2} \mathrm{PO}_{4}$, bubbled with a $95 \% \mathrm{O}_{2}-5 \% \mathrm{CO}_{2}$ mixture, and had a final $\mathrm{pH}$ of 7.3. All experiments were performed at room temperature.

Electrophysiological recording

Extracellular recordings of field excitatory postsynaptic potentials (fEPSPs) were obtained from the dendritic region of the CA1 region of the hippocampus using glass micropipettes (1-2 M $\Omega$ ) filled with superfusion solution. 
Whole-cell recordings of excitatory postsynaptic currents (EPSCs) were obtained from somata of pyramidal neurons of the CA1 region by means of the blind patch clamp technique (Blanton et al. 1989). The pipettes for whole-cell recording were filled with $130 \mathrm{mM} \mathrm{CH} \mathrm{CHO}_{3}, 130 \mathrm{mM}$ $\mathrm{CsOH}, 0.05 \mathrm{mM}$ EGTA, $5 \mathrm{mM}$ HEPES, $1 \mathrm{mM} \mathrm{MgCl}_{2}$, $1 \mathrm{mM} \mathrm{NaCl}$, and $5 \mathrm{mM}$ QX314 and displayed resistances between 4.5 and $5 \mathrm{M} \Omega$. To isolate glutamatergic dual component EPSCs, slices were perfused with picrotoxin $(50 \mu \mathrm{M})$ and CGP $35348(200 \mu \mathrm{M})$ to block $\gamma$-aminobutyric acid type $A\left(\mathrm{GABA}_{\mathrm{A}}\right)$ and type $\mathrm{B}\left(\mathrm{GABA}_{\mathrm{B}}\right)$ receptors, respectively. Voltage-activated sodium and potassium channels were blocked by QX-314 and $\mathrm{CsOH}$, applied intracellularly via the recording pipette. Currents were recorded with a switched voltage clamp amplifier (SEC10L; NPI Electronics, Tamm, Germany) with switching frequencies of $80 \mathrm{kHz}$ ( $25 \%$ duty cycle). Series resistance was monitored and continuously compensated in bridge mode. Neuronal input resistance was measured by injecting hyperpolarizing current pulses $(300 \mathrm{~ms},-10 \mathrm{mV})$.

EPSCs and fEPSPs were evoked by stimuli $(0.033 \mathrm{~Hz}$, 4-5 V, $20 \mu \mathrm{s})$, delivered via a bipolar tungsten electrodes insulated to the tip ( $5 \mu \mathrm{m}$ tip diameter) and positioned in the Schaffer collateral-commissural pathway. To determine the magnitude of the NMDA receptor contribution to responses in the presence of riluzole $(1 \mu \mathrm{M})$, we measured the charge/voltage transfer of the pharmacologically isolated dual component fEPSPs and EPSCs before and after the application of the competive NMDA receptor antagonist D-(-)-2-amino-5-phosphono-pentanoic acid (D-AP5; $100 \mu \mathrm{M}$ ) - this compound was chosen for these experiments because it is highly selective for NMDA receptors and shows rapid penetration into in vitro tissue slices and can also be rapidly washed out.

All experiments were performed at room temperature at a holding potential of $-60 \mathrm{mV}$. The recordings were filtered $(3 \mathrm{kHz})$ and the digitized $(9 \mathrm{kHz})$ data were stored using a Power Macintosh G3 computer by a data acquisition and evaluation program (Pulse v. 8.5; Heka electronic $\mathrm{GmbH}$, Lambrecht, Germany).

Statistical analysis was carried out using the Student's paired $t$ test to compare the values of $10 \mathrm{~min}$ of a stable baseline (control), and after application of D-AP5. $P<0.05$ was considered as a significant difference. Data are presented as mean \pm SEM.

\section{Results}

Effects of riluzole on synaptic transmission

In previous studies it has been shown that riluzole (5-20 $\mu \mathrm{M})$ depresses glutamatergic synaptic responses in hippocampal slices and autaptic microculture neurons (MacIver et al. 1996; Martin et al. 1993; Prakriya and Mennerick 2000) by pre-synaptic mechanisms such as the inhibition of voltage-activated sodium and/or N- and P/Qtype calcium channels (Huang et al. 1997; Song et al. 1997; Stefani et al. 1997). Here, the amplitude and area under the curve (charge transfer) of glutamatergic dual component EPSCs, mediated by AMPA- and NMDA-receptors, were concentration-dependently reduced by the application of $1 \mu \mathrm{M}$ and $10 \mu \mathrm{M}$ riluzole (EPSC amplitude $(1 \mu \mathrm{M})$ $88.5 \pm 6.1 \%, \quad(10 \mu \mathrm{M}) \quad 44.5 \pm 13.9 \% ; \quad$ EPSC charge transfer $(1 \mu \mathrm{M}) 61.8 \pm 7.3 \%,(10 \mu \mathrm{M}) \quad 49.2 \pm 13.3 \%$; $n=7$; Fig. $1 ; P<0.05)$. Albeit with no clear concentration-response relationship, riluzole also affected the decay of the EPSC and reduced the time constant $\tau$ to $74.9 \pm 8.5$ and $83.6 \pm 8.1 \%$ for 1 and $10 \mu \mathrm{M}$, respectively (Fig. 1). Both concentrations were significantly different to control $(P<0.05)$ but not to each other $(P>0.05)$.

Determination of the fraction of functional NMDA receptors after the application of riluzole $(1 \mu \mathrm{M})$

For the measurement of AMPA and NMDA receptor components mediating a single-evoked response, we

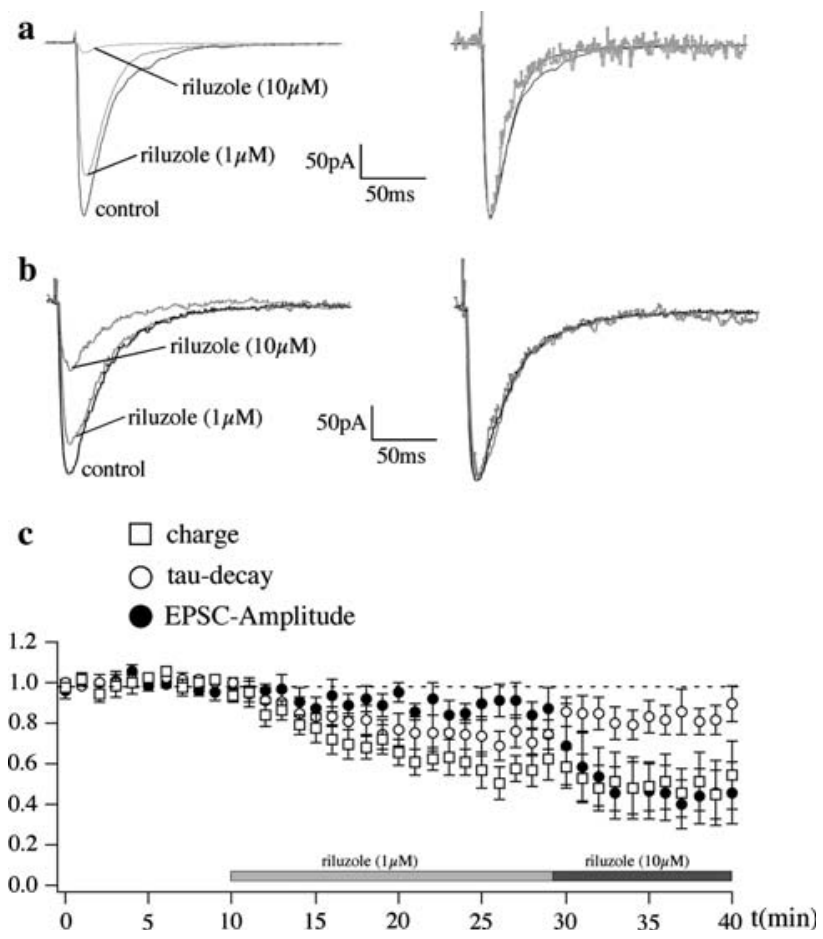

Fig. 1 Riluzole, concentration-dependently reduced dual component EPSC charge and amplitude. a, b The application of 1 and $10 \mu \mathrm{M}$ riluzole reduced EPSC amplitude. Representative traces are shown, original (left), normalized (right). Each traces in each figure recorded from one neuron, respectively. c Averaged data showing the effect of riluzole on EPSC amplitude, charge and time constant $\tau$ 
analysed the EPSC with different parameters and at different times following the stimulus (see Clark and Collingridge 1995; Fig. 2a). This is illustrated by the current-voltage (I-V) relationship (Fig. 2a); the initial slope of the response (10-60\% before the peak) is believed to be mainly mediated by AMPA receptors, whereas the amplitude of the later response (measured at $80 \mathrm{~ms}$ after the stimulus) displayed the expected NMDA receptor I-V function. As a further parameter, we assessed the charge transfer of the EPSC. After the EPSC responses were stable, either under control conditions or in the presence of riluzole $(1 \mu \mathrm{M})$, D-AP5 $(100 \mu \mathrm{M})$ was applied to ensure complete block of NMDA receptors. Under control conditions, D-AP5 reduced the initial slope and the response amplitude at $80 \mathrm{~ms}$ after the initial stimulation to $75.9 \pm 12.7$ and $46.6 \pm 10.3 \%$, respectively $(n=7$; Fig. $2 \mathrm{~b}$, c, both $P<0.05)$. During the application of riluzole, the D-AP5-induced effect on the "AMPA receptor" and the "NMDA receptor"-mediated components was similar and showed no statistically significant difference to experiments in the absence of riluzole. The initial slope was decreased to $77.8 \pm 13.2 \%$ and the amplitude of the response at $80 \mathrm{~ms}$ was $37.2 \pm 6.6 \%(n=7$; Fig. $2 \mathrm{~b}$, c, both $P<0.05$ compared to control but $P>0.05$ compared to riluzole). These results demonstrate that the proportion of active NMDA receptors was not affected by the presence of riluzole. However, the application of D-AP5 did indeed affect the amplitude of the dual component EPSC as well as the initial slope indicating that these parameters were clearly not exclusively mediated by AMPA receptor activation under our experimental conditions. Therefore, measurement of the charge transfer during the EPSC seemed to be a more precise parameter for the assessment of the magnitude of the contribution of NMDA receptor activation to this glutamateric synaptic signal. The charge transfer was calculated as the area under the curve of the EPSC. The decrease of the charge transfer of the EPSC with D-APV under control conditions did not differ from that in the presence of riluzole (control: $49.3 \pm 11.7 \%$; riluzole: $53.9 \pm 5.1 \% ; \mathrm{p}>0.05, \mathrm{n}=7$; Fig. $2 \mathrm{c}$ ). In other words, riluzole did not affect the fraction of functional NMDA receptors contributing to the EPSC, neither when EPSC amplitude at $80 \mathrm{~ms}$ was assesssed (control: $54.5 \pm 10.7 \%$, riluzole: $63.4 \pm 6.3 \%, \quad P>0.05$ ) nor when EPSC charge transfer was used as a quantifier (control: $50.5 \pm 11.3 \%$, riluzole: $46.2 \pm 4.4 \% ; P>0.05$; Fig. 2d).

In the next set of experiments we investigated the effects of riluzole on NMDA receptor contribution to synaptic potentials under somewhat more physiological conditions by performing extracellular field potential recordings without clamping the neurons at a specific membrane potential. As a measurement parameter we again calculated the fEPSP "voltage" transfer i.e. the area under the fEPSP curve. Riluzole $(1 \mu \mathrm{M})$ per se decreased fEPSPs to $70.0 \pm 5.9 \%(n=8$; Fig. 3a). When D-AP5 was applied, the "additional" change in the fEPSP evoked in control slices and those already exposed to riluzole showed no significant difference (fEPSP control: $73.5 \pm 4.0 \%$; riluzole: $81.2 \pm 5.9 \% ; P>0.05, n=10$; Fig. $3 b$ ). The fraction of activated NMDA receptors under control conditions therefore did not differ significantly from those in the presence of riluzole (fEPSP control: $30.0 \pm 6.3 \%$; riluzole: $26.5 \pm 9.5 \% ; P>0.05, n=10$; Fig. $3 \mathrm{c}$ ).

\section{Discussion}

Memantine is approved for the therapy of moderate to severe Alzheimer's disease, but preclinical data indicate high therapeutic potential in many other diseases related to neurodegeneration (Parsons et al. 1999; Rammes et al. 2008; Wenk et al. 2006). Riluzole is the only medication approved for the treatment of ALS and has been registered as a neuroprotective agent in several countries. On the other hand, riluzole has also been considered for therapeutic use in dementia and epilepsy (Doble 1996; Gordon 2005; Miller et al. 2007; Parsons and Danysz 2002; Van Damme et al. 2005). Lamotrigine, gabapentin and the related pregabalin are registered for therapy in epilepsy (Rogawski 2006; Zipp et al. 1993) and phosphophenytoin is in phase II trials for stroke and ischaemia. In other words, in some CNS disorders, treatment with NMDA receptor antagonists might have to be in combination with other anti-glutamatergic agents-the best example of which would seem to be with riluzole in ALS (Goodall and Morrison 2006; McGeer and McGeer 2005; Van Den Bosch et al. 2006; Weiss et al. 2004).

It is therefore important to consider whether there would still be a sufficient number of active NMDA receptors to allow for any additional effects of an NMDA receptor antagonist with such combinations. Furthermore, in vitro and in vivo experiments have shown that riluzole has a higher potency to decrease the NMDA-evoked responses than that of non-NMDA receptors (see Mantz 1996). Under such assumptions it might be concievable that the contribution of NMDA receptors underlying the dual component EPSC is significantly reduced in the presence of a GRI like riluzole.

In the present study, we demonstrated that the fraction of activated NMDA receptors during synaptic transmission to CA1 hippocampal neurons remained constant in the presence of the glutamate release inhibitor riluzole, which would indicate that additional effects would indeed be possible with an NMDA receptor antagonist during combination therapy. 
Fig. 2 The fraction of activated NMDA receptors under control conditions did not differ from those in the presence of riluzole. a, left Voltage-dependence of dual-component EPSCs. The symbols on the EPSC indicate where the AMPA and NMDA receptor-mediated synaptic components were measured; the slope between 10 and $60 \%$ of peak amplitude (open circles) and the amplitude at $80 \mathrm{~ms}$ following the stimulus (closed circles), respectively. a, right The corresponding currentvoltage plot for the same cell. b Representative traces, original (left), normalized (right), showing the effect of D-AP5 $(100 \mu \mathrm{M})$ on the EPSC responses with (below) and without (top) riluzole. c Average of all experiments: DAP5 reduced the initial slope, the amplitude at a latency of $80 \mathrm{~ms}$ (left) and the charge of the EPSC (right). In the presence of riluzole, the D-AP5induced effect on the AMPA receptor and the NMDA receptor component was similar and showed no statistically significant difference. $\mathbf{d}$ The proportion of active NMDA receptors was not attenuated in the presence of riluzole a

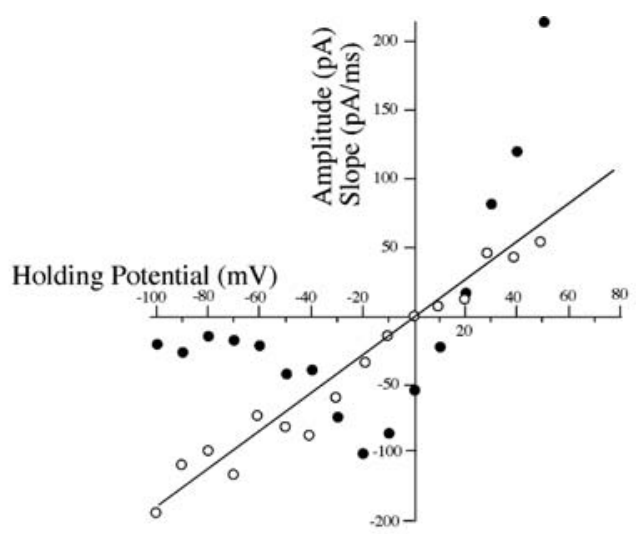

b $\operatorname{AP} 5(100 \mu \mathrm{M})$
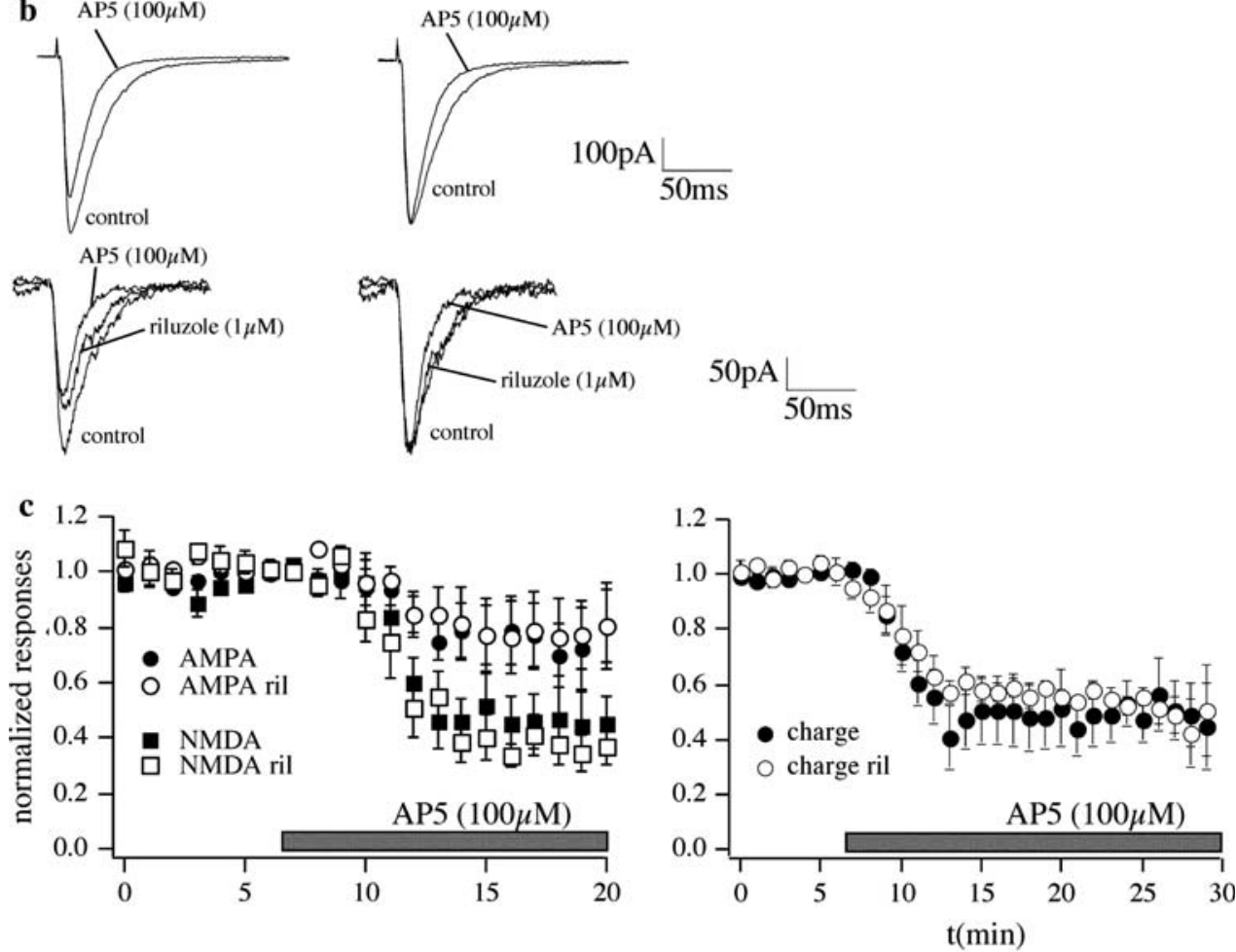

Despite extensive studies, the precise mechanism of action of riluzole remains elusive. However, effects on voltage-activated $\mathrm{Na}^{+}$channels (Benoit and Escande 1991), background $\mathrm{K}^{+}$-channels (Duprat et al. 2000), GABA uptake ((Mantz et al. 1994)) and voltage-activated $\mathrm{Ca}^{2+}$ channels (Huang et al. 1997) have been suggested. Nontheless, riluzole clearly decreases the synaptic release of glutamate (Cheramy et al. 1992; Martin et al. 1993; Umemiya and Berger 1995) and this effect is probably secondary to inhibition of voltage-activated $\mathrm{Na}^{+}$channels (Doble 1996; MacIver et al. 1996; Yokoo et al. 1998). Other recent findings indicate that riluzole not only decreases glutamate release, but also enhances glutamate uptake (Azbill et al. 2000; Frizzo et al. 2004). Interestingly, 

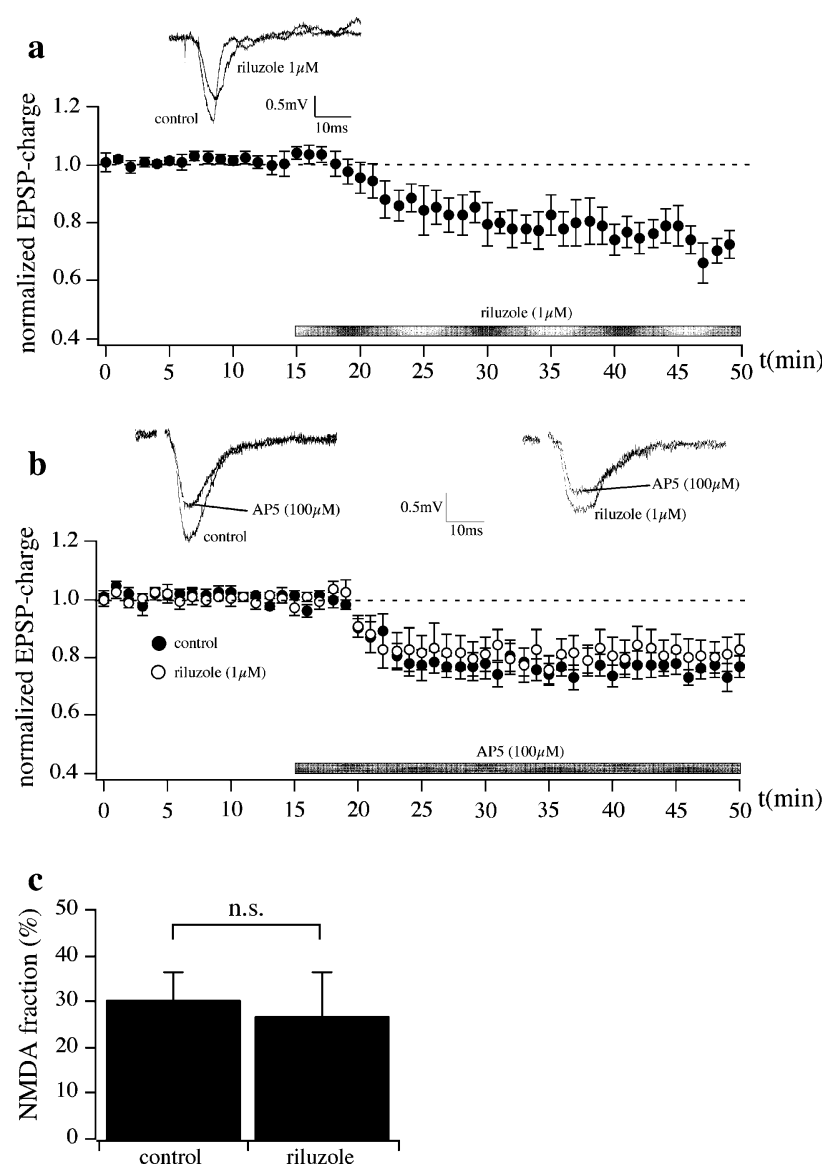

Fig. 3 Extracellular recordings, without clamping the neurons, demonstrating similar results for riluzole on the contribution of NMDA receptors to the synaptic signal. As a measurement parameter we calculated the fEPSP charge. a Riluzole $(1 \mu \mathrm{M})$ per se decreased fEPSP charge. b When D-AP5 was applied, the charge of the fEPSP evoked in control slices and those already exposed to riluzole $(1 \mu \mathrm{M})$ showed no significant difference. $\mathbf{c}$ The fraction of activated NMDA receptors under control conditions did not differ from those in the presence of riluzole $(1 \mu \mathrm{M})$

this effect was reported for concentrations reached under standard clinical conditions (Frizzo et al. 2004), similar to those used in the present study.

Whatever, the MoA on glutamate release/uptake, such effects agree well with the results of the present study in which riluzole concentration-dependently reduced isolated dual-component EPSCs in CA1 neurons.

At synapses of CA1 pyramidal neurons, where glutamate is rapidly cleared from the synaptic cleft, the decay time of synaptic currents is determined primarily by the deactivation time constants of AMPA and NMDA receptors (Silver et al. 1996). This is believed to be the main factor shaping the decay of EPSCs at cortical synapses (Hestrin 1992). Although measurements at a holding potential of $-60 \mathrm{mV}$ normally provide the best separation of AMPA and NMDA receptor-mediated components of a dual component EPSCs (Clark and Collingridge 1995), in the present experiments, the application of D-AP5 also affected both the amplitude of the dual component EPSC and also the initial slope indicating that these parameters were not exclusively associated with AMPA receptor activation. As such, the measurement of changes in the charge transfer of the EPSC in the presence of D-APV was deemed to be the most precise parameter for the assessment of the magnitude of NMDA receptor contribution to the synaptic signals recorded in the present experiments. These results were confirmed under more physiological conditions, when recording extracellulary from a population of neurons without clamping the membrane potential.

However, in the present experiments, riluzole affected both EPSC amplitude and charge transfer but had little selective effect on deactivation time. Moreover, measuring either the EPSC amplitude at a post-stimulus time of $80 \mathrm{~ms}$ or the charge transfer of pharmacologically isolated dual component EPSCs before and after the application of the NMDA receptor antagonist D-AP5 demonstrated that the fraction of activated NMDA receptors under control conditions did not differ from those in the presence of riluzole.

There is compelling evidence that abnormal activation of NMDA receptors and NMDA receptor-mediated excitotoxicity is involved in many CNS disorders (Rothstein 1995; Shaw and Ince 1997; Wenk et al. 2006). Consequently, the NMDA receptor antagonist memantine has been shown to have therapeutic potential in preclinical models of various neurodegenerative diseases and shows clear clinical symptomatic improvement in Alzheimer's disease (Danysz and Parsons 2003; Parsons et al. 1999, 2007). Another promising approach to ameliorate glutamatergic dysfunction might be the use of memantine in combination with selective inhibitors of glutamate release to gain additional therapeutic benefits and further reduce possible side effects. GRIs show therapeutic limitations; however, e.g., although riluzole has been shown to prolong the survival of motor neuron in ALS, its effects on the progression of disease are not consistent (Bensimon et al. 1994; Lacomblez et al. 1996). The combination of riluzole with NMDA receptor antagonists may therefore be more clinically useful in ALS patients to prolong neural survival (Goodall and Morrison 2006; McGeer and McGeer 2005; Van Den Bosch et al. 2006; Weiss et al. 2004). In fact, memantine has been shown to have therapeutic effects in a mouse model of ALS (Wang and Zhang, 2005). Furthermore, memantine also shows antiepileptic activity (Parsons et al. 1999) which might be useful in combination with gabapentin or pregabalin, two further modulators of synaptic release, particularly of glutamate, through direct actions on release machinery (Rogawski 2006).

The results of the present study clearly demonstrates that NMDA receptors may be a valid pharmacological target during treatment with glutamate release inhibitors. 
Open Access This article is distributed under the terms of the Creative Commons Attribution Noncommercial License which permits any noncommercial use, distribution, and reproduction in any medium, provided the original author(s) and source are credited.

\section{References}

Arundine M, Tymianski M (2003) Molecular mechanisms of calciumdependent neurodegeneration in excitotoxicity. Cell Calcium 34:325-337

Azbill RD, Mu X, Springer JE (2000) Riluzole increases high-affinity glutamate uptake in rat spinal cord synaptosomes. Brain Res 871:175-180

Beal MF (1995) Aging, energy, and oxidative stress in neurodegenerative diseases. Ann Neurol 38:357-366

Benoit E, Escande D (1991) Riluzole specifically blocks inactivated Na channels in myelinated nerve fibre. Pflugers Arch 419:603609

Bensimon G, Lacomblez L, Meininger V (1994) A controlled trial of riluzole in amyotrophic lateral sclerosis. ALS/Riluzole Study Group. N Engl J Med 330:585-591

Blanton MG, Lo Turco JJ, Kriegstein AR (1989) Whole cell recording from neurons in slices of reptilian and mammalian cerebral cortex. J Neurosci Methods 30:203-210

Burnashev N, Monyer H, Seeburg PH, Sakmann B (1992) Divalent ion permeability of AMPA receptor channels is dominated by the edited form of a single subunit. Neuron 8:189-198

Chen HS, Lipton SA (1997) Mechanism of memantine block of NMDA-activated channels in rat retinal ganglion cells: uncompetitive antagonism. J Physiol (Lond) 499(Pt 1):27-46

Chen HSV, Pellegrini JW, Aggarwal SK, Lei SZ, Warach S, Jensen FE, Lipton SA (1992) Open-channel block of $N$-methyl-Daspartate (NMDA) responses by memantine-therapeutic advantage against NMDA receptor-mediated neurotoxicity. J Neurosci 12:4427-4436

Cheramy A, Barbeito L, Godeheu G, Glowinski J (1992) Riluzole inhibits the release of glutamate in the caudate nucleus of the cat invivo. Neurosci Lett 147:209-212

Clark KA, Collingridge GL (1995) Synaptic potentiation of dualcomponent excitatory postsynaptic currents in the rat hippocampus. J Physiol 482(Pt 1):39-52

Danysz W, Parsons CG (2002) Neuroprotective potential of ionotropic glutamate receptor antagonists. Neurotox Res 4:119-126

Danysz W, Parsons CG (2003) The NMDA receptor antagonist memantine as a symptomatological and neuroprotective treatment for Alzheimer's disease preclinical evidence. Int J Geriatric Psychiatry 18:S23-S32

Diener HC (1998) Multinational randomised controlled trial of lubeluzole in acute ischaemic stroke. European and Australian Lubeluzole Ischaemic Stroke Study Group. Cerebrovasc Dis 8:172-181

Doble A (1996) The pharmacology and mechanism of action of riluzole. Neurology 47:S233-S241

Duprat F, Lesage F, Patel AJ, Fink M, Romey G, Lazdunski M (2000) The neuroprotective agent riluzole activates the two $\mathrm{P}$ domain $\mathrm{K}(+)$ channels TREK-1 and TRAAK. Mol Pharmacol 57:906912

Frizzo ME, Dall'Onder LP, Dalcin KB, Souza DO (2004) Riluzole enhances glutamate uptake in rat astrocyte cultures. Cell Mol Neurobiol 24:123-128

Goodall EF, Morrison KE (2006) Amyotrophic lateral sclerosis (motor neuron disease): proposed mechanisms and pathways to treatment. Expert Rev Mol Med 8:1-22
Gordon PH (2005) Advances in clinical trials for amyotrophic lateral sclerosis. Curr Neurol Neurosci Rep 5:48-54

Hestrin S (1992) Activation and desensitization of glutamateactivated channels mediating fast excitatory synaptic currents in the visual cortex. Neuron 9:991-999

Huang CS, Song JH, Nagata K, Yeh JZ, Narahashi T (1997) Effects of the neuroprotective agent riluzole on the high voltage-activated calcium channels of rat dorsal root ganglion neurons. J Pharmacol Exp Ther 282:1280-1290

Krieger C, Lanius RA, Pelech SL, Shaw CA (1996) Amyotrophic lateral sclerosis: the involvement of intracellular $\mathrm{Ca}(2+)$ and protein kinase C. Trends Pharmacol Sci 17:114-120

Lacomblez L, Bensimon G, Leigh PN, Guillet P, Meininger V (1996) Dose-ranging study of riluzole in amyotrophic lateral sclerosis. Amyotrophic lateral sclerosis/Riluzole Study Group II. Lancet 347:1425-1431

Löscher W, Rundfeldt C, Honack D (1993) Low doses of NMDA receptor antagonists synergistically increase the anticonvulsant effect of the AMPA receptor antagonist NBQX in the kindling model of epilepsy. Eur J Neurosci 5:1545-1550

MacIver MB, Amagasu SM, Mikulec AA, Monroe FA (1996) Riluzole anesthesia: use-dependent block of presynaptic glutamate fibers. Anesthesiology 85:626-634

Mantz J (1996) Riluzole. CNS Drug Rev 2:40-51

Mantz J, Laudenbach V, Lecharny JB, Henzel D, Desmonts JM (1994) Riluzole, a novel antiglutamate, blocks GABA uptake by striatal synaptosomes. Eur J Pharmacol 257:R7-R8

Martin D, Thompson MA, Nadler JV (1993) The neuroprotective agent riluzole inhibits release of glutamate and aspartate from slices of hippocampal area ca1. Eur J Pharmacol 250:473-476

McGeer EG, McGeer PL (2005) Pharmacologic approaches to the treatment of amyotrophic lateral sclerosis. BioDrugs 19:31-37

Miguel-Hidalgo JJ, Alvarez XA, Cacabelos R, Quack G (2002) Neuroprotection by memantine against neurodegeneration induced by beta- amyloid(1-40). Brain Res 958:210-221

Miller RG, Mitchell JD, Lyon M, Moore DH (2007) Riluzole for amyotrophic lateral sclerosis (ALS)/motor neuron disease (MND). Cochrane Database Syst Rev CD001447

Muir KW, Lees KR, Hamilton SJ, George CF, Hobbiger SF, Lunnon MW (1995) A randomized, double-blind, placebo-controlled ascending dose tolerance study of 619C89 in acute stroke. Ann N Y Acad Sci 765:328-329

Parsons CG, Danysz W (2002) ALS. In: Lodge D, Danysz W, Parsons CG (eds) Therapeutic potential of ionotropic glutamate receptor antagonists and modulators. F.P. Graham Publishing Co, New York, pp 540-562

Parsons CG, Danysz W, Quack G (1998) Glutamate in CNS Disorders as a target for drug development: an update. Drug News Perspect 11:523-569

Parsons CG, Danysz W, Quack G (1999) Memantine is a clinically well tolerated $\mathrm{N}$-methyl-D-aspartate (NMDA) receptor antagonist-a review of preclinical data. Neuropharmacology 38:735767

Parsons CG, Gruner R, Rozental J, Millar J, Lodge D (1993) Patch clamp studies on the kinetics and selectivity of $N$-methyl-Daspartate receptor antagonism by memantine (1-amino-3, 5dimethyladamantan). Neuropharmacology 32:1337-1350

Parsons CG, Stoffler A, Danysz W (2007) Memantine: a NMDA receptor antagonist that improves memory by restoration of homeostasis in the glutamatergic system-too little activation is bad, too much is even worse. Neuropharmacology 53:699723

Plaitakis A, Fesdjian CO, Shashidharan P (1996) Glutamate antagonists in amyotrophic lateral sclerosis: a review of their therapeutic potential. CNS Drugs 5:437-456 
Prakriya M, Mennerick S (2000) Selective depression of low-release probability excitatory synapses by sodium channel blockers. Neuron 26:671-682

Rammes G, Danysz W, Parsons CG (2008) Pharmacodynamics of memantine: an update. Curr Neuropharmacol 6:55-78

Rogawski MA (2006) Diverse mechanisms of antiepileptic drugs in the development pipeline. Epilepsy Res 69:273-294

Rothstein JD (1995) Excitotoxicity and neurodegeneration in amyotrophic lateral sclerosis. Clin Neurosci 3:348-359

Shaw PJ, Ince PG (1997) Glutamate, excitotoxicity and amyotrophic lateral sclerosis. J Neurol 244:S3-S14

Silver RA, Colquhoun D, Cullcandy SG, Edmonds B (1996) Deactivation and desensitization of non-NMDA receptors in patches and the time course of EPSCs in rat cerebellar granule cells Deactivation and desensitization of non-NMDA receptors in patches and the time course of EPSCs in rat cerebellar granule cells. J Physiol Lond 496:891

Song JH, Huang CS, Nagata K, Yeh JZ, Narahashi T (1997) Differential action of riluzole on tetrodotoxin-sensitive and tetrodotoxin-resistant sodium channels. J Pharmacol Exp Ther 282:707-714

Stefani A, Spadoni F, Bernardi G (1997) Differential inhibition by riluzole, lamotrigine, and phenytoin of sodium and calcium currents in cortical neurons: implications for neuroprotective strategies. Exp Neurol 147:115-122

Traynor BJ, Bruijn L, Conwit R, Beal F, O'Neill G, Fagan SC, Cudkowicz ME (2006) Neuroprotective agents for clinical trials in ALS: a systematic assessment. Neurology 67:20-27

Umemiya M, Berger AJ (1995) Inhibition by riluzole of glycinergic postsynaptic currents in rat hypoglossal motoneurones. $\mathrm{Br} \mathrm{J}$ Pharmacol 116:3227-3230
Van Damme P, Dewil M, Robberecht W, Van Den Bosch L (2005) Excitotoxicity and amyotrophic lateral sclerosis. Neurodegener Dis 2:147-159

Van Den Bosch L, Van Damme P, Bogaert E, Robberecht W (2006) The role of excitotoxicity in the pathogenesis of amyotrophic lateral sclerosis. Biochim Biophys Acta 1762:1068-1082

Wang R, Zhang D (2005) Memantine prolongs survival in an amyotrophic lateral sclerosis mouse model. Eur J Neurosci 22:2376-2380

Weiss MD, Weydt P, Carter GT (2004) Current pharmacological management of amyotrophic. Expert Opin Pharmacother 5:735746

Wenk GL, Zajaczkowski W, Danysz W (1997) Neuroprotection of acetylcholinergic basal forebrain neurons by memantine and neurokinin B. Behav Brain Res 83:129-133

Wenk GL, Parsons CG, Danysz W (2006) Potential role of $N$-methylD-aspartate receptors as executors of neurodegeneration resulting from diverse insults: focus on memantine. Behav Pharmacol $17: 411-424$

Yokoo H, Shiraishi S, Kobayashi H, Yanagita T, Yamamoto R, Wada A (1998) Selective inhibition by riluzole of voltage-dependent sodium channels and catecholamine secretion in adrenal chromaffin cells. Naunyn-Schmied Arch Pharmacol 357:526-531

Zipp F, Baas H, Fischer PA (1993) Lamotrigine-antiparkinsonian activity by blockade of glutamate release. J Neural Transm Parkinsons 5:67-75 